\title{
Development of a Novel Metastable Composite Material
}

\author{
G R Bradley ${ }^{[1]}$, P M MacKenzie ${ }^{[2]}$ \\ ${ }^{[1]}$ Now at AMRC with Boeing, Department of Mechanical Engineering, University of Sheffield, Sheffield, \\ S1 3JD, UK (email g.bradley@sheffield.ac.uk)

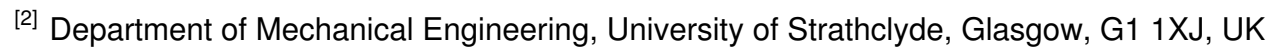 \\ (corresponding author, email peter.mackenzie@strath.ac.uk)
}

\begin{abstract}
The development of a new family of mouldable metastable composite materials has been demonstrated. Their special quality is derived from the ability to maintain the matrix as a supercooled liquid or gel whose solidification can be triggered mechanically, as desired, by a user. This paper describes some aspects of the development work. In particular, the following are explained: the choice of matrix material; the use of additives to enhance the properties of the matrix; and the selection of reinforcement fibre. As part of the work, some mechanical testing was performed on several variations of one matrix-fibre pair and, to demonstrate the potential of such materials, some comparisons were made with a possible competitor material, a glass-reinforced urethane. It was shown that the metastable material could be formulated to provide mechanical properties which would make it suitable for applications such as orthopaedic casting, splinting and body armour, and in items of sports equipment, these being areas where its mouldability could be particularly desirable.
\end{abstract}

Keywords: metastable composite, mouldable, orthopaedic, body armour, sports equipment.

\section{Notation}

$\mathrm{T}_{\mathrm{m}}=$ melting temperature

$\Delta H^{F}=$ molar heat of fusion

$\mathrm{M}=$ molar mass

$\rho=$ density (at, or extrapolated to, $T_{m}$ )

$\mathrm{C}_{\mathrm{p}}=$ specific heat capacity (at, or extrapolated to, $\mathrm{T}_{\mathrm{m}}$ )

$V_{f}=$ fibre volume fraction 


\section{INTRODUCTION}

In general, composite materials may be moulded only once, and at a particular point in time determined by their production process and the nature of the matrix material. Once the moulded form has been fixed by the curing of the matrix material, it is not possible, in the case of thermosetting matrices, or, in general, desirable, in the case of thermoplastic ones, to remould them. Obviously, the functionality of a material is constrained by these factors. The metastable composite materials described here overcome such limitations by allowing the material to be moulded to the desired form and then solidified, as and when required. In the present example, the material relies on a matrix, principally consisting of a metastable salt hydrate, which will readily supercool and thereby remain in a fluid and mouldable state. The fibrous/particulate reinforcement and matrix are contained within a flexible container and, once the desired object has been formed, a trigger mechanism, which initiates recrystallisation of the supercooled matrix, is activated, and full solidification of the matrix follows rapidly. The nature of the matrix material also allows the process cycle to be repeated quite readily, returning the matrix to the supercooled state through the addition of energy, typically in the form of heat, with no apparent degradation of properties.

\section{THE MATERIAL}

\subsection{Matrix Composition}

It was found that by addition of various additives and reinforcements to hydrated salt matrices, material with useful structural properties could be obtained.

Marcus [1] lists the properties of twenty-five salt hydrate phase change materials (these were being assessed for use in heat storage devices in which their exothermic reaction of recrystallisation was to be exploited) The range of their properties is summarised in Table 1. The suitability of a candidate matrix material for use in a metastable composite depends on several factors. Qualitative considerations include:

i. The hydrate must be stable, to a certain degree, or readily rendered stable using additives, when in the supercooled liquid state;

ii. The process of conversion from the solid to supercooled state liquid state must be convenient to the user;

iii. The material, when solidified, must retain suitable mechanical properties throughout its required range of operating temperatures;

iv. Ideally, the matrix should be non-hazardous and easily confined;

v. A low heat of crystallisation is preferred - the energy to be dissipated on solidification should be kept to a minimum consistent with functionality; 
For development of the concept presented here, sodium acetate trihydrate (SAT) was selected, this salt substantially satisfying the criteria outlined above; its chemical and physical properties are listed in Table 2. It is non-hazardous and does not degrade materials that may conveniently be used to contain it, such as flexible PVC film. Its melting point of $58{ }^{\circ} \mathrm{C}$ allows it to have acceptable mechanical properties at room temperature, whilst it can be melted easily by immersion in hot water. It has a density of $1.45 \mathrm{~g} . \mathrm{cm}^{-3}$, which is important with regard to achieving an acceptably high strength to weight ratio in the final solid composite condition. The latent heat of fusion, $160.7 \mathrm{~kJ}_{\mathrm{kg}}{ }^{-1}$, means that the heat input required to melt the material, and subsequently dissipated on recrystallisation, is low by comparison with other hydrates (for example sodium thiosulphate pentahydrate $\left(\mathrm{Na}_{2} \mathrm{~S}_{2} \mathrm{O}_{3} .5 \mathrm{H}_{2} \mathrm{O}\right)$ has a value of 200 $\left.\mathrm{kJ} \mathrm{kg}^{-1}\right)$. In the supercooled state at room temperature, it has a viscosity similar to that of water and on crystallisation it forms a brittle white solid.

\subsection{Additives}

An undesirable property of SAT is its tendency to exhibit incongruent melting; that is, the hydrate separates into its constituent parts, sodium acetate and water. Over repeated cycles of phase change, the separation can become cumulative, as the water diffuses only slowly through the solid to rehydrate the sodium acetate. This can promote uncontrolled crystallisation of the supercooled salt and localised inhomogeneity of the matrix. The addition of water and/or a thickening agent prevents separation into the anhydrous salt and water. The addition of water transforms the system from a melting salt hydrate to a saturated aqueous solution. The addition of a thickening agent can force the anhydrous salt to be maintained in suspension, thereby contributing to more consistent, repeatable rehydration [1].

Although the presence of excess water increases the stability of the SAT, it is introduces a major reduction in the overall strength of the material. On the other hand, the addition of cellulose type compounds, including starch and hydroxyethyl cellulose (HEC), was found to improve the stability of the supercooled state without degrading the toughness of the solid phase to an unacceptable degree. HEC, which is widely used commercially as a thickening agent, has a similar chemical structure to starch, consisting of a cellulose polymer with hydroxyethyl side chains. It is available in various viscosity grades and is commercially marketed as Cellosize [2].

Test samples were produced using various grades of HEC, but the most promising results were obtained using the QP-100MH grade, this producing the greatest viscosity of the various grades available, (the abbreviation HEC refers to the manufacturer's QP-100MH grade throughout this text unless otherwise stated). Small amounts of HEC were added to the matrix; weight ratios in the range $0.5 \%$ to $10 \%$ of HEC to SAT were assessed. At the $10 \%$ level, the mixture was close to being saturated, thorough mixing proved difficult, and there was a tendency for coagulated regions of HEC to form in the supercooled liquid phase. An 
added benefit of the gel type consistency of the mixture so produced was that it prevented excessive displacement of the matrix occurring at areas of high pressure when the material was being solidified, important in the proposed applications; thus, the likelihood of matrix deficient regions occurring within the composite material was reduced.

\subsection{Fibre/Particulate Reinforcement}

As an extension to the work being reported here, consideration has been given to the addition of glass, carbon and aramid fibres to a metastable matrix. To a greater or lesser degree, adhesion between the fibres and matrix was found to be poor, although it should be noted that no pre-treatment of the fibres had been carried out and this may be worth further investigation.

Conversely, cellulose fibres, in the form of cotton yarn, demonstrated excellent bonding with the matrix. Furthermore, when HEC was added to the SAT, failure of the composite occurred by fast fracture, rather than by the progressive debonding observed when no stabilising additive was present.

\subsection{Containment of the Metastable Composite Material in the Supercooled State}

Due to the liquid/gel nature of metastable composite materials when in the supercooled state, the matrix and fibre combination have to be enclosed within a container. The ability to mould the material to the desired form, prior to initiating solidification, means that the container must be flexible. A large variety of polymeric materials lend themselves to this application.

\subsection{Crystallisation Initiation}

One of the properties of a metastable composite material is that recrystallisation, and therefore solidification, can be undertaken in a controlled manner. Numerous techniques have been employed to initiate crystallisation of supercooled salts. Solmon [3] states that the initiation of solidification is the same for all materials, being dependent on the difference in free energy between the liquid and solid phases, and that this occurs by one of three methods: homogeneous nucleation, heterogeneous nucleation or epitaxial growth. Several techniques for initiating crystallisation are detailed in various US patents $[4,5,6,7,8,9]$, these typically involved the rubbing together of two metal surfaces or crack opening and closure, the result being heterogeneous nucleation. The patents state that the addition of a seeding crystal and ultrasonic techniques are also suitable. The authors employed a small metal disc (see Figure 1) containing fissures in its surface. The disc was designed so that when it was subjected to "snap-through" buckling, sudden opening and closing of the crack tips in the fissures occurred, and this was sufficient to initiate localised crystallisation of the hydrate, from which a chain reaction produced complete solidification of the material. As this occurs, the latent heat of fusion (or crystallisation) is released and, as the heat is dissipated, the strength of the matrix material increases. Plainly, the time from initiation of crystallisation to 
the attainment of full strength is substantially dependent upon the geometry of the object in question and the temperature and properties of the surrounding environment. Thin shell type structures have a high rate of cooling, and this promotes a small and consistent crystal size throughout the matrix and thereby the optimum strength of the material is achieved. The time required to attain maximum strength for the metastable composite material under investigation, with a shell type structure and thickness of $1-2 \mathrm{~mm}$, was found to be $10-15$ minutes at room temperature.

\section{SOME MECHANICAL PROPERTIES}

\subsection{Test Procedure}

The test results reported here were used as input to the development process. In total, five formulations of the SAT matrix metastable composite material were prepared for tensile testing: a commercially available glass-reinforced urethane (GRU) was subjected to identical test procedures so that the results from the metastable material could be compared with what might be considered a candidate material for comparable applications, e.g. in orthopaedic casting.

Test plaques, from which the tensile test coupons were cut, were produced by tack welding the cotton gauze fibres to PVC sheet; the PVC was then welded together along three edges to produce an envelope with one end remaining open. The SAT/HEC matrix material was mixed in granular form and then transferred to the PVC envelope, which was then heated in a thermostatically controlled hot water bath at $70^{\circ} \mathrm{C}$. Once the matrix had melted, it was spread over the cotton gauze until the fibres were fully impregnated. The envelope was then transferred to a hydraulic press and compressed using a nominal pressure of $2.25 \mathrm{MPa}$. The pressure was maintained until the material had cooled to room temperature: crystallisation was then initiated, still under pressure. Once the latent heat of fusion had dissipated, the plaque was removed from the press. Figure 2 depicts a test plaque on removal from the hydraulic press.

Parallel-sided specimens of length $150 \times 20 \mathrm{~mm}$ were cut from the test plaques removed from the PVC enclosures, and to each, end tabs were attached to remove the likelihood of failure at the grips. The specimens consisted of three variations on the matrix consistency, the amount of HEC added to the SAT, and three on the number of layers of fibres added. The fibres consisted of loosely woven cotton gauze with a $90^{\circ}$ biaxial weave, the fibres running along the length and width of the specimens. Details of the various formulations are shown in Table 3.

The glass reinforced urethane test coupons were cut from a test plaque that consisted of four layers of the material, this being comparable to the number of layers used in orthopaedic casting. The six specimens tested were made up of four layers with a mean total thickness of 
$4.2 \mathrm{~mm}$. The results obtained for the GRU are similar to those quoted by Houlton and Brearley [10] for a similar material, $25 \mathrm{MPa}$ for the working strength. In contrast, the results compare less favourably with those of Rowley and Pratt [11], who obtained a value of $40 \mathrm{MPa}$ for the yield strength, for the same material used by Houlton and Brearley [10]. (Note: the GRU used in this work is a later development of the material described in [10 \& 11].)

Metastable composite formulations were classified using a two figure number, of the format $X X X / Y Y$; where $X X X-100$ equals the amount of HEC in grams added to 100 grams of SAT and $Y Y$ equalled the number of layers of cotton gauze. Hence, 105/8 means that the matrix consisted of a mixture of $5 \mathrm{~g}$ of HEC being added to $100 \mathrm{~g}$ of SAT and the material contained 8 layers of cotton gauze; 100/16 means that the matrix consisted solely of SAT and the specimen contained 16 layers of cotton gauze.

Tensile testing was performed using a Zwick 1445 test frame using a $10 \mathrm{kN}$ load cell. A test speed of $5 \mathrm{~mm} \cdot \mathrm{min}^{-1}$ was employed and displacement was measured using a knife-edge extensometer with a gauge length of $25 \mathrm{~mm}$. An XY analogue plotter was used to record both the applied load and extensometer displacement. A typical stress-strain plot for the GRU and 105/32 metastable composite material is shown in Figure 3.

\subsection{Test Results}

The tensile and yield strengths, $0.2 \%$ secant modulus, and failure strain were evaluated: the results are shown in Figure 4. The nature of the material is such that scatter in specimen performance might be expected. However, it is also reasonable to assume that the population distribution of the test results will be approximately normal and it follows that confidence intervals for small samples may be evaluated quite safely by use of the Student tdistribution. Table 4 and Figure 4 summarise the results of this assessment.

Although the metastable composite material formulations tested did not show an exact yield point, a change in the response is noted as the matrix begins to fail and the load is transferred to the fibre reinforcement. A yield point was therefore determined by using a technique described by Meredith [12] for assessing the yield strength of textiles as the load/displacement plots had a similar shape. A tangent to the load/displacement curve is drawn parallel to a line connecting the origin to the breaking point, the point of tangency being considered the yield point. The GRU exhibited a near linear load/displacement relationship followed by failure: its yield strength has therefore been classed as identical to the tensile strength for comparison purposes.

For four of the metastable formulations, the tensile strength of the material was greater than that returned by the $\mathrm{GRU}$, the metastable formulations having values ranging from $29-32$ $\mathrm{MPa}$, compared with $27 \mathrm{MPa}$ for the GRU. The 105/8 formulation of the metastable 
composite material returned a value of $17 \mathrm{MPa}$. Although the test plaques for all the metastable composite formulations were produced using the same procedure, the reduction in the number of layers of cotton reinforcement in the 105/8 specimens resulted in a significant reduction in the calculated fibre volume fraction, $V_{f}$. The 105/8 formulation returning a $V_{f}$ of $5 \%$, whereas $7-11 \%$ was achieved for the other formulations and it is probable that the reduction in tensile strength is related to this.

Due to the near linear elastic response up to failure, of the GRU, the yield strength was considered equal to the tensile strength. The yield strength of the GRU, $27 \mathrm{MPa}$, was considerably greater than that exhibited by the metastable composite formulations, which ranged from $13-16 \mathrm{MPa}$ for formulations other than 105/8.

The various formulations of the metastable composite returned $0.2 \%$ secant moduli ranging from 3.9 - 4.9 GPa, whilst the GRU returned a value of $3.4 \mathrm{GPa}$.

The GRU failure strain of $1.0 \%$ reflects the brittle nature of the material, in contrast the metastable composite formulations returned values ranging from $3.6-4.8 \%$ (except the $105 / 8$ formulation which failed at a strain of $1.5 \%$ ).

Failure of the metastable composites was due to rapid fracture at $90^{\circ}$ to the applied load, except for the 100/16 formulation, which exhibited failure of the matrix and subsequent gross deformation of the fibre reinforcement. All the metastable composite specimens exhibited extensive microcracking immediately prior to fracture. The GRU failed by progressive breaking of the glass fibres; in this case, the material remained partially intact as the weave of the material allowed the significant extension, although the specimens were no longer able to sustain the applied loads.

\section{DISCUSSION}

Metastable composite materials offer unique properties based on the ability of their matrices to exist in the supercooled state. Although only one matrix material, SAT, has been demonstrated, other candidate materials are known to possess similar properties. SAT in its supercooled state is unstable and upon crystallisation results in a brittle solid, but it was found that the addition of hydroxyethyl cellulose to the matrix resulted in an increase in stability in the supercooled state, as well as improving its toughness when solid. The increase in stability in the supercooled state means that solidification of the material can be initiated as and when required by the user using a simple mechanical trigger device. The increased viscosity resulting from the addition of HEC is also beneficial as it prevents excessive displacement of the matrix when in its liquid or gel state. The range of properties of various metastable salts means that there is potential for the final properties of the material to be tailored towards its final use. 
Addition of fibres to the SAT matrix produces a marked increase in the strength of the material. Satisfactory bonding between cotton fibres and the SAT/HEC matrix was achieved; further investigation is required in order to establish whether the use of higher strength fibres may be possible through pre-treatment of the fibres or by adopting a different matrix formulation.

The heat emitted on matrix crystallisation means that solidification of the material is not instantaneous, but depends on the surrounding environment and on the geometry of the material. Following the initiation of crystallisation, the temperature can approach that of the melting point of the SAT. This increase in temperature extends the time available for manipulation and shaping of the material, with minimal effect on the final mechanical properties.

Except for the 105/8 formulation, the various metastable combinations showed similar mechanical performance, and these were in some important respects comparable to those of a glass reinforced urethane, GRU. It appears that the tensile strength of the metastable composites could be close to that of the $\mathrm{GRU}$, at about $30 \mathrm{MPa}$; however, the yield strength of the GRU at $27 \mathrm{MPa}$ was approximately twice that of the highest result obtained for the metastable formulations. The variation between the tensile and yield strengths and failure strain of the metastable composite and GRU materials reflects the manner in which they fail. The glass fibres in the GRU fail in a brittle manner: in contrast, the metastable material exhibits a progressive breakdown that is related to failure of the matrix by microcracking, and subsequent transfer of the load to the fibres.

The $0.2 \%$ secant modulus of the $\mathrm{GRU}$, at $3.4 \mathrm{GPa}$, appeared slightly lower than that observed for the various formulations of metastable composite, with these ranging from $3.9-$ 4.9 GPa.

In summary, it has been shown that the mechanical properties of the small range of metastable composites described here could be tailored to be broadly similar to those exhibited by the GRU; these examples of the new material may be suitable for similar applications. The high failure strains which were observed, coupled with failure by microcracking of the metastable composite, may prove to be beneficial in applications where impact energy is to be dissipated. GRU solidification is activated by contact with moisture in the atmosphere and the reaction is irreversible; metastable composites can be returned, many times, to their supercooled and mouldable state by the addition of heat. The increase in temperature on crystallisation may be problematic for some potential orthopaedic uses such as emergency splinting; insulation could limit the effects of this and the increase in the time taken to attain maximum strength would allow an increase in the time that the material could be manipulated. 


\section{CONCLUSIONS}

It has been shown that structural metastable composite materials can be developed by exploiting the ability of hydrated salts to exist in a supercooled state, yet be easily triggered to solidify. By containing the matrix and fibres within a sealed flexible container, the user is able to control the initiation of crystallisation, and thus solidification. Although SAT is somewhat unstable with respect to crystallisation in its supercooled state, a greater tolerance to handling can be introduced through the addition of hydroxyethyl cellulose to the matrix. The HEC also raised the viscosity of the supercooled matrix, a desirable feature in some of the proposed applications. A combination of SAT and HEC matrix, with cotton fibre reinforcement, produced a composite material having mechanical properties comparable to those of a GRU widely used for orthopaedic casting. Such metastable composites may be cycled repeatedly between their solid and supercooled states, through the application of heat, with no appreciable degradation of their properties. 


\section{REFERENCES}

[1] Marcus, Y: Thermal energy storage (in Molten Salt Technology, editor Lovering, DG),

Plenum Press, London. 1982, pp 457-498.

[2] Cellosize Hydroxyethyl Cellulose, The Dow Chemical Company, Midland, Michigan, 2002 (available for download from http://www.dow.com/cello/res/prodlit.htm).

[3] Solomon, HD: Fundamentals of weld solidification (in ASM Handbook Volume 6: Welding, Brazing and Soldering), ASM International, Metals Park, Ohio. 1993, pp 45-54.

[4] Ferguson, RS: Heat flask, US Patent number 1,920,853, United States Patent office, 1933.

[5] Othmer, DF: Valveless chemical heater, US Patent number 2,220,777, United States Patent Office, 1940.

[6] Stanley, J; Hoerner, GL: Reusable heat pack containing supercooled solution and means for activating same, US Patent Number 4,077,390, United States Patent Office, 1978.

[7] Kapralis, IP; Krukle, H: Trigger to initiate crystallization, US Patent number 4,379,448, United States Patent Office, 1983.

[8] Kapralis, IP; Krukle, H: Trigger to controllably initiate crystallization, US Patent number 4,460,546, United States Patent Office, 1984.

[9] Manker, CF: Activator for initiating reaction in heat pack and method for making same, US Patent number 4,872,442, United States Patent Office, 1989.

[10] Houlton, JEF; Brearley, MJ: A comparison of some casting materials, Veterinary Record, 1985, 117, pp. 55-58.

[11] Rowley, DI; Pratt, DJ: Orthopaedic bandage form splinting materials, Clinical Materials, 1986, 1, pp. 1-8.

[12] Meredith, R (editor): The mechanical properties of textile fibres, North Holland Publishing Company, Amsterdam, 1956. 


\begin{tabular}{|c|c|c|c|c|c|}
\hline $\begin{array}{c}\mathrm{T}_{\mathrm{m}} \\
\left({ }^{\circ} \mathrm{C}\right)\end{array}$ & $\begin{array}{c}\Delta \mathrm{H}^{\mathrm{F}} / \mathrm{M} \\
\left(\mathrm{kJ} \cdot \mathrm{kg}^{-1}\right)\end{array}$ & $\begin{array}{c}\rho_{\text {solid }} \\
\left(\mathrm{g} \cdot \mathrm{cm}^{-3}\right)\end{array}$ & $\begin{array}{c}\rho_{\text {liquid }} \\
\left(\mathrm{g} \cdot \mathrm{cm}^{-3}\right)\end{array}$ & $\begin{array}{c}\mathrm{C}_{\mathrm{p}_{\text {solid }}} \\
\left(\mathrm{kJ}^{-1} \cdot \mathrm{kg}^{-1}\right)\end{array}$ & $\begin{array}{c}\mathrm{C}_{\text {Pilquid }} \\
\left(\mathrm{kJ}^{-1} \mathrm{~K}^{-1} \cdot \mathrm{kg}^{-1}\right)\end{array}$ \\
\hline $8.1-172$ & $108.8-288$ & $1.45-2.65$ & $1.41-2.28$ & $1.09-1.98$ & $1.57-3.72$ \\
\hline
\end{tabular}

Table 1: Range of properties for salt hydrate phase change materials listed by Marcus [1].

\begin{tabular}{|c|c|c|c|c|c|}
\hline Chemical formulation & $\begin{array}{c}\mathrm{T}_{\mathrm{m}} \\
\left({ }^{\circ} \mathrm{C}\right)\end{array}$ & $\begin{array}{c}\Delta \mathrm{H}^{\mathrm{F}} / \mathrm{M} \\
\left(\mathrm{kJ} . \mathrm{kg}^{-1}\right)\end{array}$ & $\begin{array}{c}\rho_{\text {solid }} \\
\left(\mathrm{g} . \mathrm{cm}^{-3}\right)\end{array}$ & $\begin{array}{c}\mathrm{C}_{p_{\text {solid }}} \\
\left(\mathrm{kJ}^{-1} \mathrm{~K}^{-1} \cdot \mathrm{kg}^{-1}\right)\end{array}$ & $\begin{array}{c}\mathrm{C}_{\text {piquid }} \\
\left(\mathrm{kJ} \mathrm{K}^{-1} \cdot \mathrm{kg}^{-1}\right)\end{array}$ \\
\hline $\mathrm{NaCH}_{3} \mathrm{CO}_{2} \cdot 3 \mathrm{H}_{2} \mathrm{O}$ & 58 & 160.7 & 1.45 & 1.98 & 3.54 \\
\hline
\end{tabular}

Table 2: Properties of sodium acetate trihydrate [1].

\begin{tabular}{|c|c|c|c|c|c|}
\hline $\begin{array}{c}\text { SAT } \\
(\mathrm{g})\end{array}$ & $\begin{array}{c}\text { HEC } \\
(\mathrm{g})\end{array}$ & $\begin{array}{c}\text { HEC } \\
\text { concentration } \\
(\%)\end{array}$ & $\begin{array}{c}\text { Number of layers cotton } \\
\text { gauze reinforcement } \\
\left.\text { (biaxial weave at } 90^{\circ}\right)\end{array}$ & $\begin{array}{c}\text { Mean } \\
\text { thickness } \\
(\mathrm{mm})\end{array}$ & $\begin{array}{c}\text { Sample } \\
\text { Identification }\end{array}$ \\
\hline 100 & 0 & 0 & 16 & 0.73 & $100 / 16$ \\
\hline 100 & 2.5 & 2.44 & 16 & 1.03 & $102.5 / 16$ \\
\hline 100 & 5 & 4.76 & 16 & 1.11 & $105 / 16$ \\
\hline 100 & 5 & 4.76 & 32 & 2.06 & $105 / 32$ \\
\hline 100 & 5 & 4.76 & 8 & 0.83 & $105 / 8$ \\
\hline
\end{tabular}

Table 3: Details of metastable composite material tensile test specimens.

\begin{tabular}{|c|c|c|c|}
\hline $\begin{array}{c}\text { Sample } \\
\text { Identification }\end{array}$ & $\begin{array}{c}\text { Tensile Strength (MPa) } \\
\text { and 95\% confidence } \\
\text { limits }\end{array}$ & $\begin{array}{c}\text { Yield Strength (MPa) } \\
\text { and 95\% confidence } \\
\text { limits }\end{array}$ & $\begin{array}{c}\text { Strain at failure (\%) } \\
\text { and 95\% confidence } \\
\text { limits }\end{array}$ \\
\hline $100 / 16$ & $31.3 \pm 5.1$ & $13.3 \pm 0.8$ & $4.7 \pm 0.7$ \\
\hline $102.5 / 16$ & $31.7 \pm 1.5$ & $14.0 \pm 0.5$ & $4.5 \pm 0.5$ \\
\hline $105 / 16$ & $31.5 \pm 1.7$ & $14.3 \pm 1.0$ & $4.7 \pm 0.5$ \\
\hline $105 / 32$ & $28.5 \pm 3.3$ & $16.0 \pm 2.0$ & $3.6 \pm 0.5$ \\
\hline $105 / 8$ & $16.5 \pm 2.5$ & $11.0 \pm 1.7$ & $1.7 \pm 0.6$ \\
\hline GRU & $27.3 \pm 1.2$ & $27.3 \pm 1.2$ & $1.0 \pm 0.1$ \\
\hline
\end{tabular}

Table 4: Summary of mechanical test results. 


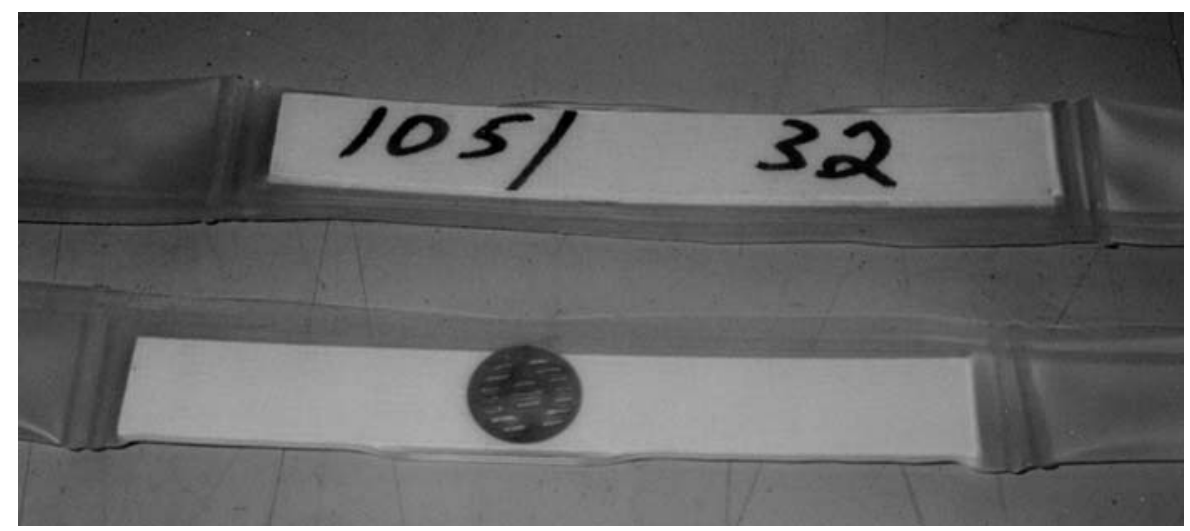

Figure 1: Metastable composite specimens exhibiting the disc used to initiate crystallisation and flexible PVC film containment.

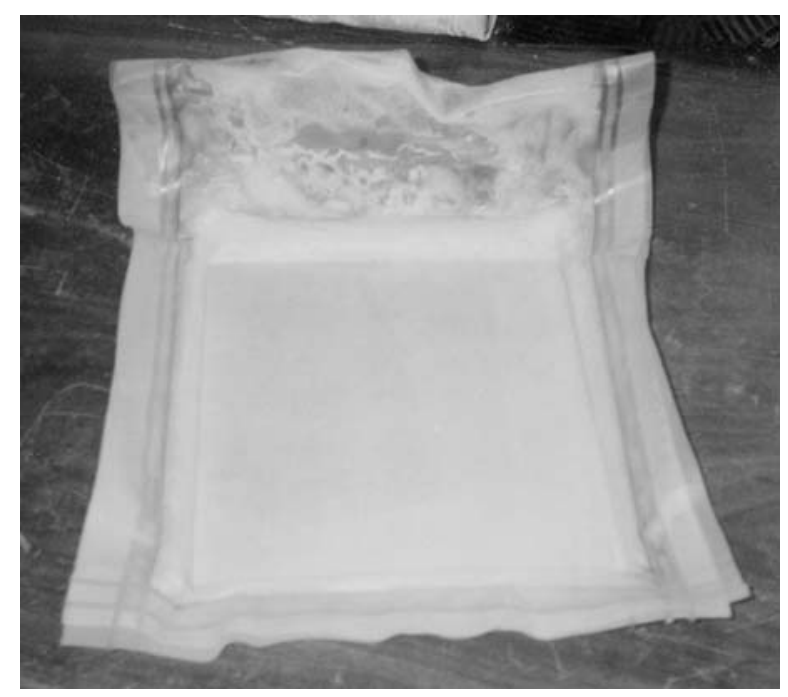

Figure 2: Metastable composite test plaque from which the tensile test coupons were cut. 


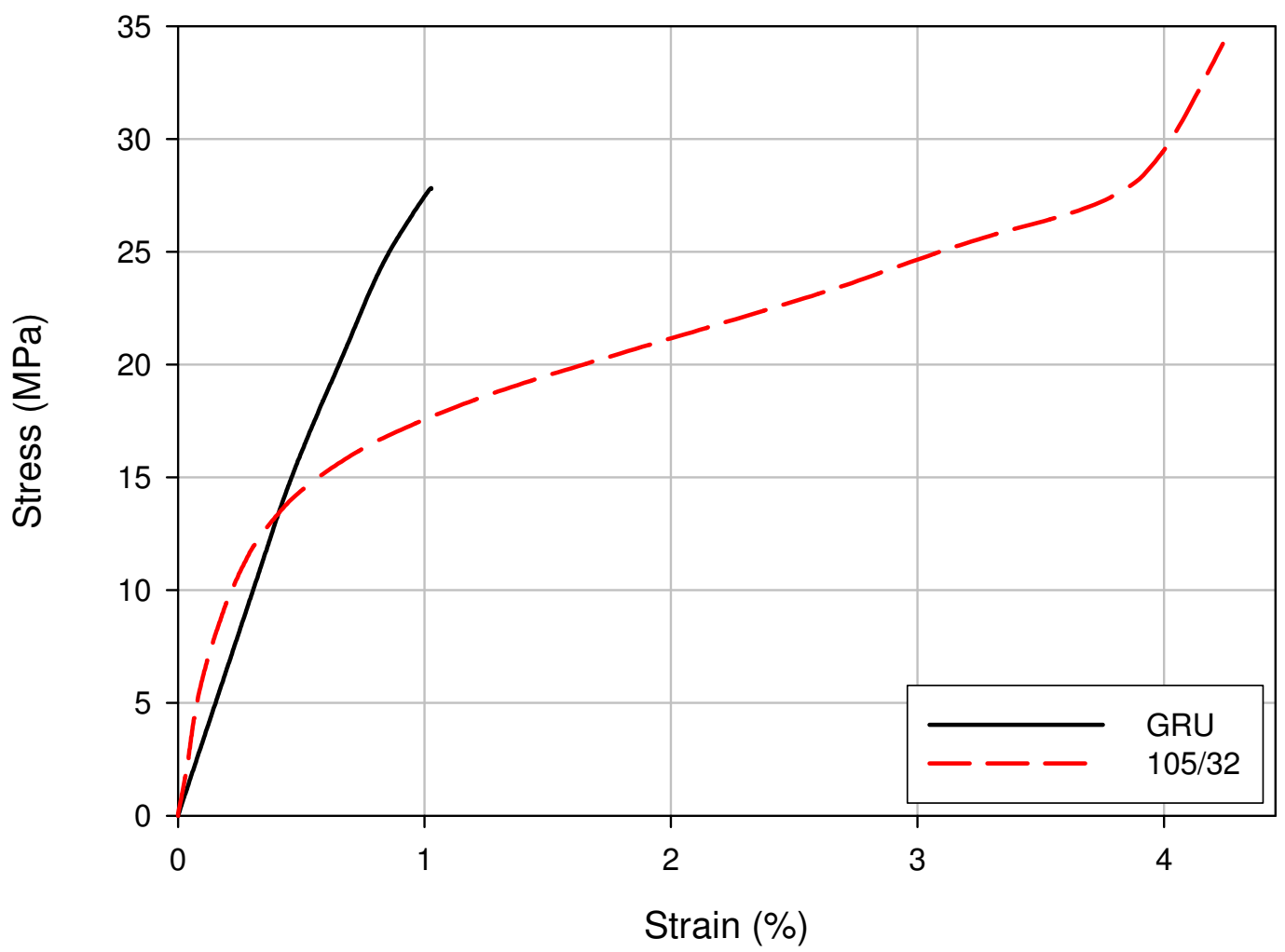

Figure 3: Typical stress-strain plot for a GRU and 105/32 metastable composite materials. 


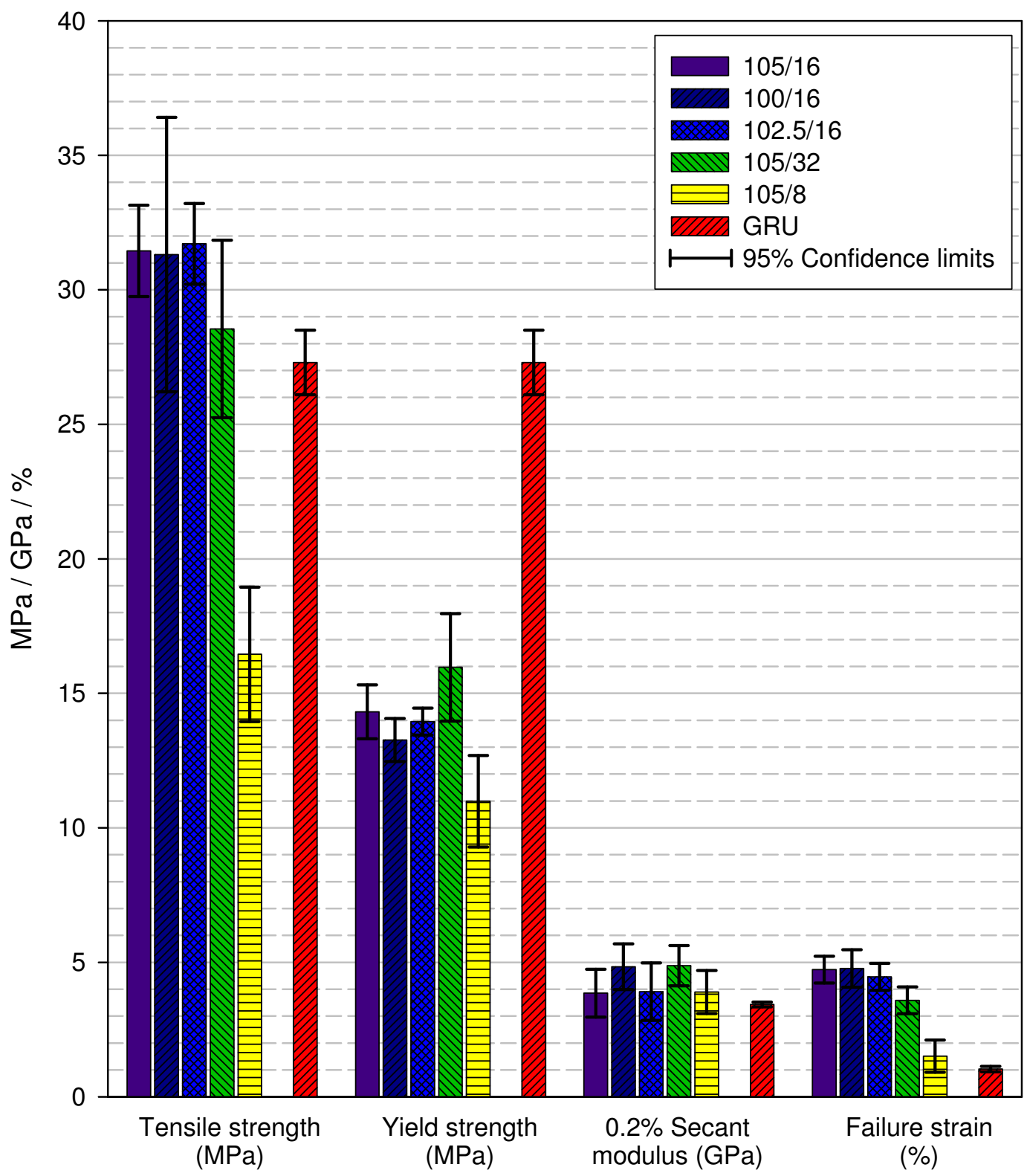

Figure 4: Mechanical properties (mean values and $95 \%$ confidence limits) of various formulations of a cotton gauze reinforced SAT/HEC metastable composite material and a GRU. 